\title{
Transcript of WAC 8 Digital \\ WAE Bioarchaeological Ethics Panel Discussion, 29 August 2016 and Resolution on Ethical Use of Digital Bioarchaeological Data
}

Brenna R. Hassett, Institute of Archaeology, University College London, 31-34 Gower Street, London, WC1H OPY, UK

E-mail: b.hassett@ucl.ac.uk

Carolyn Rando, Institute of Archaeology, University College London, 31-34 Gower Street, London, WC1H OPY, UK

Emmy Bocaege, School of Anthropology and Conservation, Marlowe Building, The University of Kent, Canterbury, Kent CT2 7NR, UK

Marta Alfonso Durruty, Department of Sociology, Anthropology, and Social Work, Kansas State University, 204 Waters Hall, 1603 Old Claflin Place, Manhattan, KS 66506, USA

Cara Hirst, Institute of Archaeology, University College London, 31-34 Gower Street, London, WC1H OPY, UK

Siân Smith, Institute of Archaeology, University College London, 31-34 Gower Street, London, WC1H OPY, UK

Priscilla Ferreira Ulguim, School of Science, Engineering and Design, Teesside University, Middlesbrough, Tees Valley TS1 3BX, UK

Suzanna White, Institute of Archaeology, University College London, 31-34 Gower Street, London, WC1H OPY, UK

Andrew Wilson, School of Archaeological and Forensic Sciences, University of Bradford, Bradford, West Yorkshire BD7 1DP, UK

\section{ABSTRACT}

This is the transcript of the panel discussion held at the close of the WAC 8 Digital Bioarchaeological Ethics Panel. Given the rapid pace of emerging technology that allows for the creation of digital bioarchaeological data, including representations of $3 \mathrm{~d}$ shapes, the panel was convened to discuss common issues and dilemmas that arise from the introduction of new ways of creating, visualizing, storing, and disseminating data derived from human 
remains. The discussants represent expertise in bioarchaeology, forensic anthropology/archaeology, and palaeoanthropology and have experience in different sectors covering museums, collections management, medical, legal, bioarchaeological and anthropological research. The discussion covers the advantages of creating 'virtual' bodies using digital bioarchaeological data, and also the many potential hurdles in creating, using, and sharing this data. Finally, the text of the resolution submitted by the panel to the World Archaeological Congress and adopted at the 8th Annual Meeting is reproduced in full.

Résumé: Il s'agit de la transcription du groupe de discussion mené en clôture du panel du WAC 8 sur l'éthique bioarchéologique numérique. Au vu de l'avancée rapide de la technologie émergente donnant lieu à la création de données bioarchéologiques numériques, dont de représentation de formes tridimensionnelles, le panel a été formé pour traiter des problèmes et dilemmes couramment soulevés à l'apparition de nouvelles façons de créer, visualiser, stocker et disséminer les données dérivées de restes humains. Le panel était composé d'experts en bioarchéologie, anthropologie/archéologie judiciaire et paléoanthropologie possédant de l'expérience dans divers secteurs, dont la muséologie, la gestion de collections et la recherche médicale, judiciaire, bioarchéologique ou anthropologique. La discussion porte sur les bienfaits de la création de corps «vitruels» à l'aide de données bioarchéologiques numériques et des nombreux obstacles éventuels posés à la création, à l'utilisation et au partage desdites données. Le texte de la résolution soumise par le panel au World Archaeological Congress et adoptée lors de la 8e Assemblée annuelle est enfin reproduit dans son intégralité.

Resumen: Esta es la transcripción del debate del panel celebrado al cierre del Panel de Ética Bioarqueológica Digital del Octavo Congreso Arqueológico Mundial (WAC-8). Dado el rápido ritmo de la tecnología emergente que permite la creación de datos bioarqueológicos digitales, incluyendo representaciones de formas tridimensionales, el panel fue convocado para discutir problemas y dilemas comunes que surgen de la introducción de nuevas formas de crear, visualizar, almacenar y diseminar datos derivados de restos humanos. Los participantes representan experiencia en bioarqueología, antropología/arqueología forense y paleoantropología, y tienen experiencia en diferentes sectores que cubren museos, administración de colecciones, investigación médica, legal, bioarqueológica o antropológica. La discusión cubre las ventajas de crear cuerpos "virtuales" utilizando datos bioarqueológicos digitales, y también los muchos obstáculos potenciales para crear, utilizar y compartir estos 
datos. Finalmente, se reproduce íntegramente el texto de la resolución presentada por el panel al Congreso Mundial de Arqueología y adoptado en la Octava Reunión Anual.

\section{KEY WORDS}

Digital bioarchaeology, Ethics, WAC resolution, Human remains

What follows is a transcript from the extremely productive round table discussion between the speakers at the 8th World Archaeological Congress in a special invited session on advances in Digital Bioarchaeological Methods and Ethics, led by Brenna Hassett, Carolyn Rando, and Emmy Bocaege. The panel of participants is comprised of (in order of arrangement around the table): Emmy Bocaege (EB), Carolyn Rando (CR), Andrew Wilson (AW), Brenna Hassett (BH), Priscilla Ferreira Ulguim (PFU), Cara Hirst (CH), Marta Alfonso Durruty (MAD), Suzzana (Suzy) White (SW), and Siân Smith (SS). The round table was chaired by Brenna Hassett, who also edited the transcript below for coherence. ${ }^{\star}$ The discussion led to the drafting of the resolution adopted by WAC 8 on the ethics of digital bioarchaeology, reproduced in full at the end of the transcript. All participants in the round table were signatories to the resolution.

* Note on transcript editing: repeated words and filler words like 'um' and 'like' have been pared down. Some off-topic discussion has been removed, and all participants have been allowed to suggest small textual changes to improve the accuracy of the transcript or, where meaning is unclear, to clarify intent.

\section{Transcript of Digital Bioarchaeological Ethics Panel Discussion, 29th August, 2016}

\section{[Checking recording.]}

BH: OK! So this is the panel discussion for the Theme 4F Session on digital bioarchaeology and ethics. So we have all of the authors here at the table and we're just going to kind of go in a semi-structured roundtable response.

I've got a couple things that I would kind of like everyone to have a chance to have a say on, and then if people have other questions that they'd kind of like the table to answer. So it's going to be very loose structure but basically ... we've all brought up a lot of issues; a lot of them are about access to remains; a lot of them are about the ethics of accessing remains, and the ethics of then making those remains available to the public either online or through 3D printing. And there are a couple sort of dif- 
ferent ways to sort of structure our talk on that; most of which are in the back of my head. I think so what I'd like to start with actually is:

Essentially: our virtual bodies, digital bioarchaeological representations of human tissue-are they ethically safer to share and disseminate than human remains? Do virtual remains represent something different than physical remains?

So if everyone can just go around and give a kind of short response and we'll see where we get with that.

So, Emmy's had a lot of experience with the collections, we've heard quite a bit about your work; do you think that's virtual remains are safer?

EB: Depends on what you mean by safe. I think there is definitely a bit of a double standard in terms of how we treat physical remains and virtual remains and virtual remains. So, no I don't think they are safer. I think there needs to be some guidance about why and how people upload models, first of all, and secondly, print them.

BH: OK.

Carolyn.

CR: I do agree with what you say; I mean about the printing and having access, and I do think there are more ethical issues in there which are very similar to actual physical remains. However once they are printed in that permissions has been granted then I do see them as being something completely different, because the argument is often 'this was a person' and then you can no longer say that this is a person anymore, so how have they lost their personhood by being made into plastic? So, there's the original document and original value, obviously yes; but the actual replica itself, once a person's printed? No.

BH: OK

Andrew.

AW: I sort of wear a couple of hats on this I suppose. And I suppose, speaking with the conservation hat on, there is obviously a very good argument in terms of safeguarding the longevity of collections which otherwise would-particularly for the sort of very special pathological collections that we've been talking, that I was talking about-that are in essence quite irreplaceable. And they are some of the most fragile specimens as well, so certainly there; and also from an access standpoint we've been hearing of course about that. You know, these are off behind doors that are sometimes quite hard to access, and by creating a forum, creating a resource such as Digitised Diseases we were able to make, in essence, something much more available.

And I suppose from the sort of clinical standpoint there, I mean the relevance to me was in having a resource that was available that can help in the modern day, in a modern day health service. And that obviously sort of mirrors some of what we've been hearing about from forensic science 
but also we've got to bear in mind that clinicians in their training today are not able to see live patients sometimes with these conditions, which go to end point effectively in terms of the historic and the archaeological collections that we've had a chance to work with; so there is a real valid argument for making that available with modern day training in mind and some of these diseases and conditions are reemerging conditions. So-called neglected tropical diseases for instance are examples that are reemerging.

BH: Everyone loves yaws.

AW: Exactly. And our clinicians need to get to understand those as better so that's a bit of a rambling set of arguments but I think yes, there are really good reasons.

BH: Ok. I think I would come down on the side of a virtual body being safer to disseminate because of the separation between our idea of real and our idea of the artifacts. That's what I've found. I think that that's been a concept that's been around in larger archaeological practice. Like, I think you brought up the example of the peace pipe from the Smithsonian, where the Smithsonian has created $3 \mathrm{~d}$ replicas that can be used by the community group because otherwise they would destroy it, it would not last; and so because they wish to have it or have something like it they have actually taken a $3 \mathrm{~d}$ replica and left the original. Which I think is a very interesting concept. But I am really interested in how you can make virtual bodies more ethical to share and I think there is work that needs to be done there that there needs to be standards (and it's difficult to annotate my own words).

So I want to turn to Priscilla.

PFU: From a bioarchaeologist's perspective we know the view: I would say that it depends on context. So is it 'safe' from the perspective that Andrew was talking about: about conservation, and fragility and handling? Yes, it is.

So now I'm going to go to the perspective of people that come from a ... native group. So if you asked them to think about this issue, they would tell you: 'well, we do not disassociate.... anything that's printed from our remains is part of our remains'. They would claim that for burial, like the Yanomami, for example they asked for all the samples of their blood recently [to be returned]. They consider everything as part of them. There is no disassociation between personhood. So this is one perspective on how we deal with this ethical issue from the Native American point of view.

From the researcher's point of view, yes it's safe, but when you are dealing with the communities and...dealing with other aspects that involve public engagement, people are sensitive. So it will depend on the context of how it is done.

BH. OK. And, Cara. 
$\mathbf{C H}$ : Well, obviously I agree with what you're saying in terms of it means safer in terms of physical damage to the remains. As Carolyn said in her talk, it's available for public outreach because it's no longer one of a kind on some levels, and if there were damage to occur over time it wouldn't be an issue apart from money and replacement. But obviously that's got-it's a whole new thing that's approaching and guidelines need to be put in place both for public and for research and I think those two things are going to end up being incredibly separate in terms of what's allowed. I think this ends up coming down with you took material from somewhere. The original material is still kind of attached to the digital but there do need to be some separate rules in terms of how it can be given to other researchers, or used for outreach. And it may still be the original body that you took it from in terms of the institution or the museum who have regulations on what their digital material can be used for. From a researcher's as point of view I would love to have all of this available as much as at the ethically possible. Particularly with the use of geometric morphometrics, to be able to actually understand another person's collection and determine that, you know, these were the landmarks that they placed on it, this was the result that they got, demonstrate that actually, yes, this was done in that way. And if we did it in a different way using the same material we may enhance previous research and just improve on each other rather than everyone just collecting their own $3 \mathrm{~d}$ scans over and over again and damaging the original material which is...

BH: No one's in favor of measuring the same bone twenty times, that's so weird. Ok! Suzie

SW: Well, I pretty much agree with everyone. I do think digital data is safer. Ethically, there is a bit of a philosophical question with the link to the physical because i don't know if we think about it in the same way as say, photos of skulls. Although, you do tend to cite where it came from and ask for permission it's kind of more acceptable to show photographs and spread them around, maybe less so digital data; but I'm not sure. But I do think there is a problem with digital data and we are not necessarily considering it; a lot of places I've visited haven't had any restrictions on what I can do with that digital data-which means I can theoretically share it with as many people as I want. Which doesn't just have ethical implications, it has implications for their collections and the money they get and everything. So I think we do just need to consider it more, at least how we allow access and how restricted copyright is.

BH: Ok. Marta.

MAD: I agree that it might be safer from a preservation point of view, I think that is something that we all share, but I agree with Priscilla right that this is very contextual. And it depends on where you work. So I think that if you worked in Europe you would have this feeling that it's more 
OK basically to share it. But I work in the Americas and I work with Native groups, and I think that I would have to ask them. And moreover although I agree with you Brenna that an ideal would be to have certain standard procedures, it will depend on how the group sees it, and whether or not they associated images with the remains, which, I suspect is something that some of the groups I work with wouldn't. It's all part of identity and it's all charged with [...] personhood and the ownership of their own history, right. So I think it's quite delicate.

The other part is the curatorial aspect. In the sense that it comes from museums, like the material I work with comes from museums, and ultimately they are the stewards of that material. So I think that some of the regulations would have to come from them. And so I think although... we're just getting our feet wet in this area this is a new and it's creating all these questions

What are the ethical implications? What are the applications? What are the limits of the applications, and what is good data and what isn't good data? So it's exciting in that sense but I think that my worry, I guess, is that we're going to run into different problems so I think it's going to be a complicated trajectory.

BH: I think you are very right.

[Laughter.].

Ok. Siân.

SS: So I think from the forensics perspective there are issues with introducing that kind of evidence to the courtroom. And is it going to help us with controlling the bias that you might get from shooting human remains if you have to show them as evidence to a jury, and is that going to create bias? Sorry, we know that it does create bias, but is it gong to create the same bias if you have a digital version of it, a $3 \mathrm{~d}$ version of it? And having a $3 \mathrm{~d}$ version also gives us this kind of other medium for us to communicate with a jury and with a lay audience, something that is maybe more tactile and can help someone to understand: a reconstruction of a situation that might be quite complicated or is difficult for people to think about. It kind of allows us to censor it without losing any of the data. I think there are people subsiding into this already. And I suppose what we were talking about earlier, from an outreach perspective, we want to have real material that we can take to help educate and inspire people to think about our field and having the real, having something tactile, is much more effective.

But we do just have to be careful that we're doing it, that there is a necessity to doing it and we're not just doing it for the sake of it. That's maybe quite a good control for us to have: that we're not just doing it for fun

EB: When you mention control again, that's a big aspect overall of digital bioarchaeology, basically. Because I think somebody mentioned in one 
of the talks that once it's out there you don't know who's going to download it, who's going to print, and that's scary for bioarchaeologists. And especially in terms of, for example, museums, who really want to make sure that remains are displayed ethically if you lose that control you're don't know...

Yeah.

MAD: I think that there's also a question of patrimony. There's a patrimony burden on the museum or the country so the decision making whether it has value as patrimony or not so I think there's several questions that we-

\section{[Loud paper rustling.]}

BH: Actually I think that's a fairly useful intro into-I do have, I have, I have a plan here.

[Laughter.]

I have control!

Yes, so, one of the things that I brought up in my talk-and obviously we have to do the structure of my talks because that's what I remember-was the idea of... This open access ideal of authors having integrity of their work which I think ties into the stuff that we've been talking about downloading $3 \mathrm{~d}$ prints, about what happens to them and about who owns them, and what community has a say in doing them. So I really wonder if one of the goals of this talk is to think about how would we even get to establishing who owns, who is the author, of $3 \mathrm{D}$ data. And ... I think that's what that's actually where I want to go around the table next is: just a brief statement from everyone on how we get authorship linked to the responsibility that we all have to engage with whatever community is concerned. Basically, if you are a museum and you're looking at South American remains, how do we establish that you're the author of that, you 're the owner of that? Do you have-what is the author's responsibility, I think is what I'm getting at, does that make any sense? You can adapt question and answer what you like.

[Laughter.].

So we'll go over to Emmy.

EB: I think it's right, such a big such a big question. I think one of the things is provenance, which is the thing I talked about before. You need this complex information about the remains both in the physical and the virtual world, which is a bit tricky, for example in the SketchFab collections. And so there's the issue of provenance and there's this other issue of the sort of the difference between the derived and the source data. So you have different issues here: where the specimens are housed, what museum is custodian of those specimens, what person has worked, reconstructed the models, this is important to acknowledge. And basically-for every dif- 
ferent model you would have to identify different stakeholders, which is not the case at the moment.

BH: But it's not a bad idea... Carolyn?

CR: I'm honestly not sure how to answer. You know I guess it's a bit tricky because I'm very much of the opinion nobody wants any of this stuff to get away. Because first of all, if you do consider it another person, how can you author another person? You know we're talking about... like we have, or say my institution has, like X number of skeletons; we don't own them, we are holding them, they are in our custody as custodians so I think that authorship from an institutional perspective is quite a tricky thing. And then could I then say that they were mine? This is where I get into conflict about this because I've had personal experience with researchers who've said you cannot look at this it is mine. You cannot have access to this for 10 years even though you want to have access to it.

[Laughter.]

Again it's that this is somebody's, and authorship to me denotes ownership in a way; because if I'm an author of a paper it means I've written that, I've done that, it's my project, my work.

Well, I don't argue that doing a big project like Digitised Diseases-it is your work, you do own kind of the intellectual property, but then the actual scans of cells ...? So I don't know how to answer, because I don't think that there is, for me, a clear answer-because I have an issue with the idea that we can own human remains.

Which is why, just as an aside, I own no human remains. There's nothing in my house, I refuse to have any of it. I don't want to own skulls and stuff like that; it's just like I don't feel I have the right.

BH: Andrew.

AW: Nice segue...

No, it's a great thing, and what made Digitised Diseases successful is having some really forward thinking from the stakeholders. Because I've worked with certain institutions since that are much as you describe; you know, very locked down, but they are thinking of their collections, and this is largely artefacts. But it was an interesting thing for me to sort of see how they attribute any scan data in the same way as they would a photograph. Seeing the commercial value in the photograph, or in the intellectual property of these collections that I'm holding. And the nice thing was there was none of that in Digitised Diseases. The ethos from the outset was very much one of Open Access, that the whole reason for doing this was making these models available for all. And creating the commons license agreement. And we chose a creative commons license agreement that was as unrestrictive as we possibly could make it, with the proviso in relation to this issue of $3 \mathrm{~d}$ printing. So it's effectively the only non-derivative. 
But otherwise you know these are models, for sharing, for use and its in the spirit of education. So I think they're, given this mention of provenance and context, you know the fact that each model has its own unique URL and we've got some explicit statements on there about ethical context. Hopefully. I mean it's really nice to hear people are using the resources as it was intended. I think in order to be freely available that open access element and licensing were key. But you know it took a lot of time at the outset to try to think about those and get those right. But as I say, forward thinking institutions that we were working with took the lead.

BH: Ok. So what I'm generally hearing, which I think is very interesting, is this idea that multiple stakeholders need to be attributed, need to be involved; and you cannot just have a kind of 'well I scanned it, it's mine, I'm going to-I'm wandering off with it now and I'm going to publish it'. And if this is going to offend... you know, small groups or a few hundred people who are already pretty offended. And so I think the multiple stakeholder involvement, the idea that when something goes up online the ownership is actually kind of that concept of attribution, that everyone is sort of involved, I'm quite fond of that. And I also really like this idea that over time we can overcome some of the authorship and the ownership issues by really doing the due diligence. This idea if you either state the traced provenance, or you state why you have still published it without tracing the provenance. And the idea that you have sort of an obligation to provide context and then in the context of that context-that's a great statement-you should be able to identify all the stakeholders and you should be able to attribute authorship if you've done all of the work you need to do. So, if you're publishing something online and you say 'I don't really know who originally scanned it'-you have a problem, that this is without context and this is not providing all of the information that it seems to me like we really need to include if we're going to be ethical about sharing this.

\section{Priscilla?}

PFU: Well. Let me approach the question, answering how I want to. [Laughter.]

So basically I think there are few issues here. First we come from different perspectives: we have the forensic side of ... things and we have archaeology and perhaps palaeoanthropology-

BH: archaeo, palaeo-

PFU: so this is going to bring us different questions when we look at who owns things and how are we going to share and so forth. First, I think we need to look at the technical aspects, or we could start with the technical aspects. First, who is doing that technical work? So, for example we need to pay attention to that, because if you hire someone to do that and you want to put that in your Ph.D., who owns that? Because that person 
did that, did an artistic work; it legally has an artistic aspect, in that there is a claim as a property, as an intellectual property.

So another thing is when you release. How do you share that? Is it going to go through SketchFab, because they can use that for advertising, and if they can use that, they can modify. You are granting them that, by the way. So, you have to pay attention to who is the third party that you are dealing with, who you are hiring or who are the people that are involved in this process, so [i.e.] the stakeholders approaching it from the tech perspective.

If you come from the forensic perspective I would say the first thing for me was giving classes about photogrammetry. The discussion with the students was 'are you going to release that?' Because...unless it's in the courtroom, I think it is a very sensitive issue if someone just opens SketchFab, and sees the cranium of his sister. We're going to end up with questions, ethically.

Questions: where are you going to save those things? What are the providers, or where are you putting this information, like Dropbox? ...So that's another technical aspect, and Dropbox may own your content! So, so again policy needs to be assessed. In South America, things are is completely different in terms of policy, because in Brazil we have been colonized before, and they love bureaucracy, so we have a single law for everything...nothing is applicable that is applicable in Europe. That's another thing that we need to acknowledge.

Another question this brings to me is: do we want data open? Like by the Open Definition? Because the Open Definition says we can share and we can modify and it can be used for any purpose: '. Any purpose?' So I think this is bringing me questions about that.

Then finally, again, because I work within with South America...with Amerindian groups, I would have to talk to them. I would have to ask consent. Although, they are part of my group, I'm technically a descendent of them. I don't feel like I can grant myself consent. I myself feel like I shouldn't go in there and just say 'Hi guys', you know, it's a long term process it's not just like 'Hi, can I have a signature?' So there are a lot of issues, and then you have to work case-by-case to ... elaborate who; and depending on how many stakeholders you are involving, who owns this? And how are you going to decide to share this, in terms of ownership and licensing? Of course, in the first instance the Creative Commons is the best solution, for example I'm trying to do the most open process I can, so my models are there if someone wants to use or look at them, I put a Creative Commons license; but it's a forensic-mock kind of thing...not involving ethical issues. 
BH: Thanks, that's I think the point being in WAC is that we get more perspectives otherwise right yes this would be held at UCL, there are a couple of us here. Cara?

$\mathrm{CH}$ : I think it's kind of goes back to how close the digital data is to the original in terms of what you believe it is: when it stops being a human body and starts being a digital collection. Because if you have collected, if you have a digital collection, and you're not sharing it with anyone at all, not even researchers... How is that any different to someone putting a 10year embargo on an archaeological collection and not letting anyone else research it? It seems equally selfish in claiming ownership over something that-I agree with Carolyn-nobody owns. And at the same time, people who curate and scan the collection have put time and money into it and should be referenced and the context needs to be provided for everything. Otherwise it's useless, as with all archaeological stuff, it's completely useless if there's not going to be any context at all in this. But as you're saying it's an incredibly complicated issue as to the cultural material, and who would be affected if this was going to be out in the public, or out in research and the groups associated with the remains.

For me I guess if someone was to apply to a museum the same way they were to look at the original skeletal information, can they not also then apply to them for the digital downloads that someone else scanned or that the museum scanned? That's just one way of maybe at least getting it out there other than having it completely open to anyone to do all that they could possibly think of doing with it. And I guess some limitations need to be put on it so it is still useful in an ethical way, but should equally be used as much as possible. Because otherwise it seems like such a horrific waste of the material we have available to us for research

BH: And also takes a very long time to scan.

$\mathrm{CH}$ : Like I would like everyone to use everything I scanned, that took a thousand hours or something to do, something ridiculous. I want other people to be able to use it and expand and then their next collection could be two thousand mandibles or whatever.

PFU: I think you should change to photogrammetry.

[Laughter.]

BH: Just line them all up and go running with the camera. I think that's going to work pretty soon.

SW: So, I have two things about this. First, it is interesting to hear about the cultural continuity in human remains, because there are collections which are essentially ancestors of people still alive. That's kind of why we have this huge reaction, that sensitivity of who is actually related to that person, whether they might be offended or not. I think, past a point in time, that should be considered less of an issue. Particularly for fossils but going into Homo sapiens as well, because just because of fossils 
are found in a country does not mean that the people now living in that area are more related than everyone else in the world. So I find it particularly... almost offensive that people claim ownership of fossils.

BH: - I think you'd have a hard time in North America...

SW: Yes, it's kind of... there's a bit of a fuzzy boundary in time; but you know from a scientific perspective it is true. Very.

[Conversational buzz, laughter.]

BH: Briefly I think-sorry I will just interrupt-I think the established practice in most U.K. museums to identify all interested parties and the descendent community. They don't necessarily have to prove descent but they need to represent sort of over ten percent of the overall interested people who could possibly claim relation. So for instance the Druids can't rebury the Avery skeletons because, while there is a religious group who claims that they are the most associated with them, there is also the rest of the UK population [...] who not want them reburied, and their voice is over the ninety percent mark in terms of who considers this. But that's just the UK case and I know in fact, particularly in North America and in Australia, and I hope increasingly in South America people are being a little bit more considerate about these issues?

PFU: South America, well, Brazil, which occupies quite a bit of that; in Brazil it's funny because actually our archaeologists are saying: 'you guys belong to this site' and they say 'no', and they [archaeologists] say 'no, you do!'. The Sambaquis, for example, is a famous case: the shell mounds. So a large percent of the archaeology in Brazil, it's about shell mounds and we don't know who they belong to, we can't trace them to anyone. It's very difficult because we don't know who we can ask. So the guys are very happy because they can go there and do whatever research they want, and they never talk about ethical issues because they say 'well, we don't know who they are'. But that doesn't mean you don't need to talk about it. O, n the other hand, ones we have, like I work with the Xokleng and the Kaingang and the traditional archaeology is saying to them 'we don't think it is'. But [they say] 'Yes it is!' So it's really a very complex discussion.

BH: And I think that Suzie's got this sort of... there's a very big dichotomy between palaeoanthropology and archaeology. [...] But I think that there are there are probably, that you've got to a point where individual cases need to be considered appropriately and I think I think that's really... But I'm sorry I interrupted you, was that point one?

SW: Yes, that was pretty much point one. And yes, like the Hobbit, that is an evolutionary dead end it does not have descendants-it has relatives, because everything is related, but it does not have descendents so I don't feel like a cultural group should own it. I believe that fossils in large should probably be kept in the geographic area because that is their context, it's inherently linked to what they look like and how they evolved. But they 
should be considered to be curated and looked after by museums instead of owned, and I feel like curators have an obligation to allow other people to study them not just say 'this is so'. That's the fossil side anyway and that does go into Homo sapiens for quite a substantial period of our evolution as well. But also from actually the collecting of digital data-it's a bit of a weird one because most collections want a copy of the data, but then places like the Natural History Museum will not charge bench fees if you are contributing information for that collection, so by giving them digital data you get kind of special access; you get to keep your seat or you don't pay and that's fine. But maybe the next people who want to come and access the data that is going to be collected, maybe they should be subject to bench fees because they haven't necessarily contributed. That kind of idea, like, I feel like the people who have put work into getting that digital data where it is should have maybe some special permissions. But I still do think it should be ultimately up to the curator because you collect data under certain conditions that have been allowed by the collection, who are in charge of things and they're not typically doing it just because they're mean and they don't want people to look at stuff, they're doing it to look after the collection.

BH: And the money to look after the collection.

SW: Yes.

BH It's an interesting point actually. Marta?

MAD: Thank you. Well, I agree with Carolyn. I don't really think anybody owns these things. So I don't I don't like the concept of ownership, but it's true that there is work, and as Andrew brought up its usually a fairly lengthy and complicated process from the technician that is kind of like, in our case, who controls and prepares the CT scan, to the person who is going to import the files and clean them-unless you're a student right?

\section{[Laughter.]}

MAD: ...Which requires you to do everything. There's a point in your career in which you only know to do certain things and other people do it, so it's very collaborative. I think giving credit-I don't see a problem with that-but that is a different from talking about 'ownership', and so you can give credit and you can do it on different levels and that is something that has to be established within a project for example, like Andrew's work, or it can be at an institutional level. Because the collections develop in different ways that contributed to the creation of the digital or printed out models or whatever it is you're doing. That, I agree with you. So I'll see you on that. You will have to have more of the institutions curating their collections to write or to make clean this data. But usually you also receive some funding, maybe from your own government, so then it should come 
to everybody or there should be some access to everything, but again access and credit have to be determined in a specific context.

So I don't think-sorry Brenna-I don't think there are sweeping solutions for all these things, because they all depend on their individual scenarios.

BH: I suspect you're right. It's not a happy thought. But we'll get there... Siân?

SS: I think we're all kind of agreeing on a very diplomatic route where there will have to be multiple stakeholders involved. But I do agree that technically the output, the $3 \mathrm{~d}$ image output, that belongs to the person that created it in terms of the intellectual property. That you need to have the permission and the guidance from the other stakeholders of the original material but we also-we keep talking about the stakeholders a lot but we have to remember that we are also stakeholders as well. We have to be careful to protect ourselves because we don't want to be responsible for being associated with you know losing - not losing control of the data, but kind of releasing it and then it being used inappropriately down the line

BH: Damien Hirst's skull...

SS: Yeah. And I did an Instagram takeover a few months ago for an organization as part of an outreach thing. So they wanted to know a bit about my research and about forensic anthropology generally and I took some photos of the collections in UCL in the institute of archaeology museum, and they were released on Instagram, and we had a discussion about them, and then afterwards I kind of thought—should I have released these photos? Is that OK? I mean there's nothing wrong with them, they were just part of the collection, but I wasn't sure afterwards whether we should have done it; because you can just download photos from Instagram, you can copy and paste them or whatever-so someone else could technically have access to that and have or change the ownership from Institute of Archaeology, to me taking the photos, to the company that I did the takeover for, to then all the people who are following me on Instagram. So, I'm not quite sure. I don't have an answer for that, I don't quite know where the boundaries are for that so its something to bear in mind I suppose in the future: social media sharing of digital media.

BH: And I think that's my-that's generally-I don't know about the institutions that you all work in but ours had a variety and at times conflicting social media guidance.

So. I think that's actually, I think that's pretty good. So what I have got, because dear God I'm not going to be able to read back through all of that... But I think it's really interesting. I think some of the key things that we have sort of come up with are essentially: we are not great at knowing who owns this stuff. We should figure that out, that seems like one of the necessary next steps is to establish a kind of path to ownership or at least 
to rights to data and I think that's something that needs to be... In some cases it seems like actually-in Digitised Diseases, it was actually easy because you went through, you discussed, you had what I can only assume were very many long meetings. But to work this out, you know, if you're working with remains with a descendant community this is not a single signature process, like Priscilla said; this is something that requires a lot of in-depth thought and would need to be reasonably project-specific. The other sort of general things that I've been hearing are the importance of context and I think that goes back to that sort of right to the data; that you can't assume that you just own the data without doing this kind of due diligence. So if you if you can't find the authors you haven't done due diligence. If you don't know who scanned it...

This would in fact going back to this sort of open question of virtual bodies; you know, are they sort of manna from heaven that is going to save us from all of the ethical issues that we face working with human remains? I mean I think that's a resounding 'No'. Is that fair? But I don't think it's unsalvageable. I don't know if anyone massively disagrees...?

What I'd like to do is just like everyone pretty much I'm going to just give one last thought if you have one or you can just shake your head and go 'no'. But just because what I'd like to do is to take this conversation and my beautiful, totally logical notes, and what we will do as organizers is try to come up with a little bit of a draft text that doesn't-that encapsulates some of the principles and we'll send it around to this group and if we feel like that text-I'm thinking like three sentences I'm not thinking like essay because, no-but if we feel that we generally agree with this as a sort of step forward then I am very interested, if everyone is willing, to put it in front of the WAC resolutions. As a best practice guideline much like the human remains statements that we've heard because I think it is important that people don't just go blitzing into that sort of...

[Interlude of audience discussion with Hanna Marie Pageau on complimentary Ethics sessions at WAC 8.]

BH: But I think ... we need to do something about this. I think we all have raised very interesting issues and so just in the last couple minutes, just if there's anything else that you want to shout out because I talk more....

Emmy any final...?

EB: I just have a brief point maybe. Because a few of your talks have also mentioned this digital protocol and sort of strategy for metadata, how to deal with tricky printing, quality control and things like that. Maybe we can have quick discussion amongst ourselves about that?

BH: Yeah I wanted to I wanted to get to $3 \mathrm{~d}$ printing and the licensing and we didn't quite get there. 
EB: Is there a way, maybe, can we find a way forward in terms of this coming towards a protocol of producing digital data.

BH. I think that's an excellent idea. I think... that's next right here and we could talk about this if everyone is able to come to a drink later? Not everyone, alright.

EB: Maybe we could put it to the people, for example Marta talked about this, and you talked about this as well, if you could maybe quickly mention...

[An attempt by conference staff is made to clear the room and 25 more minutes for discussion are negotiated.]

BH: Right so we will have bit about the data we are actually collecting!

EB: Thank you.

BH: [Laughing.] Ok then, do you have some thoughts on that Emmy?

EB: I was more thinking about the other speakers actually talked about this at length, for example Martha. She talked about the moulds and Suzie talked about...

BH: Ok and we will jump across... to

EB: Sorry I messed everything up didn't I?

[Laughter.]

BH: you changed the organization!

[Laughter.]

Actually what I might do is just go round robin and really take a yes or no maybe on whether you feel older there is a standard practice with at least the data you work with that can be set as a sort of archive standard. If you think about already exists? And then everyone that says yes I'll talk to. OK.

Would you say that there is a standardized data format that you were aware of? Like if you have an archive standard or...?

EB: I was more thinking about for example in my talk, I mentioned the idea about tags and that it's difficult to find digital models. So more about how standardized the metadata is? How easy it is to find? Which is a bit lacking at the moment I think.

BH: So Emmy, you are going to give us the question to answer then. [Laughter.]

EB: I think before uploading models for example it's important to think about how to tag it, how to ... what to write about specifically for the model, the methods used to acquire it.

CR: I'm going to get into that, and it's good because not only is it an issue about remains, it's an issue about research in general. Because as we all say, we do slightly different things despite the fact that we can all say it's physical anthropology or something like that. Physical anthropology is now being co-opted as something specific-biological anthropology is now about primates, apparently, if you go with the new AAPA's directions at 
the moment. And in the UK there's a different meaning to the US when you do bioarchaeology, palaeopathology, palaeontology... So the tagging is reasonable for this kind of thing, and I think the tagging for the software seems quite straightforward and then like the name of the protocol used, was it a published protocol. I think that having those two-the program and the protocol-together sounds like really sensible tagging. But the actual remains themselves, and how you encoded these in bioarchaeology, does have a slightly different connotation to it; one that is maybe slightly different from physical anthropology versus osteology.

BH: And it changes depending on what country you're in...?

CR: It does change depending on what country you're in.

SS: And depending on what part of the country you live in, because where I live in the US it's the opposite. All of our primatologists say physical. And all of our others say primate... the bio-cultural thing is I think why our department went that way.

BH: Andrew do you want to add to this real quick?

AW: I'm not sure about real quick...

[Laughter.].

AW: The thing about something like a project the size of Digitised Diseases is, you get-I showed you the picture of the guy scratching his head, about how we structure this-a lot of thought went into it. But of course, taking a step even further back, the sort of data that you are capturing often comes in proprietary format. And are you archiving that? Well discussions recently with ADS [Ed. Note: ADS is the Archaeology Data Service] and other partners on Digitised Diseases that are taking the archive from us; they're not interested in those proprietary formats.

Which is interesting for us, because of course if you want to go right back to what was scanned how was it scanned, and you're not going to be able to do that. So, of course then you need to look at what's the demand for formats; well of course now it's designed for certain platforms, with certain platforms in mind, versus what are longer term archival standards? And again... So I'm not going to come up with any answers I'm afraid. Simply open the can and explain why these are complex issues.

EB: I think it's an important issue, I think this is an important thing.

BH: I think we're probably not going to get far in the remaining 20 min but I think I think it's very important to raise, because we do have archiving issues and we do have data standard issues. I mean all of archaeology has this and if you've ever tried to open someone else's Harris Matrix or whatever it's really ... a mess...

[...] I'm not sure if we can standardize metadata. I think we can standardize archiving and I think that there are facilities for doing that and $\mathrm{i}$ think things like the ADS and Tdar which is the North American-but they are those are sort of standard approaches that hopefully we can use. 
Priscilla?

PFU: Yes. I think I can help Emmy with this because I did previous work. My presentation today was based on the work I did at the beginning of the year, so I had some guidelines for that, regarding the sharing of human remains in terms of $3 \mathrm{D}$ modeling...I put some writing together- "Models and metadata", so that is one thing.

Second thing, I would like to just conclude with some reflections or some questions, because as you said we started to brainstorm. So, one thing I would like to talk about, to lead with this thought, is about the 'patronizing'. I feel like sometimes we can be very patronizing about saying to people 'you cannot share an image' you know; 'you do not do this'. I feel that for me, and in my personal view, I don't think that is the best route. Of course, we need to evaluate; one thing is we are talking about red markers or we are talking about certain cases; another thing is if we are we talking about engagement or someone publishing an image, imagery, or work. So, I think there are contexts where they are acceptable, they actually encourage identification, they encourage several things. So, I think we should be very careful about our patronizing behavior, more than with ourselves, because many of us have massive accounts and we're talking to a massive public and we say to them 'do not share human remains', 'do not do this', 'do not do that'. What we actually are doing is...instigating perhaps a very dangerous behavior... we don't know where it's going to go. So that's one thing.

The final thing...is about morals. We're talking a lot about ethical issues at this table and I personally think that we should remember that especially in the case of the Amerindians... we cannot judge based on our own morals. We can't redefine, because they will tell you: 'who are you to redefine my morals? Who are you to say that you can expose or cannot expose me?' Many of them would actually allow you to expose. So, just the ethical principle ... to conclude on that.

BH: No I think it's a very good, it's a very-it's a very WAC conclusion I think. It sort of fits in so...

I'm so sorry I'm going to have to skip over if that's ok but I would like to-basically I'm going to email around and I would like the text that I email around to be the start point of a discussion. So I would-please contribute to this. I hope I have everyone's email address-but thank you very much for participating. Thank you so much.

[End recording.] 


\title{
Reproduction of Resolution on Digital Bioarchaeological Ethics Adopted by the 8th Annual World Archaeological Congress
}

\author{
Proposed at WAC-8 Kyoto, 2016 by Brenna Hassett, edited by Anne Pyburn \\ on adoption.
}

We recognise that the creation, dissemination, and curation of digital bioarchaeological data (DBD) require special consideration where it represents models of virtual human remains. In order to meet ethical standards for the treatment and display of human remains, the following conditions must be met when creating, disseminating, and curating DBD: (1) Authorship must be established by identifying all stakeholders, e.g. the curating authority, data creator, involved communities; (2) DBD should be presented in context, e.g. with metadata on archaeological context and author attribution; and (3) access and use conditions must be set on a case-by-case basis according to the needs of all stakeholders. As DBD has the potential to be of huge benefit in education, outreach, and collections preservation, we advocate a tiered hierarchy of online Open Access under Creative Commons licensing which respects the special nature of DBD and stakeholder needs including, in decreasing order of access restriction: (a) Curating Authority Regulated Access, where the curator decides access; (b) Registered User Regulated Access, where access is granted to known individuals; (c) Public View Only Access; and (d) fully Open Access.

Signatories:

Brenna Hassett, Carolyn Rando, Emmy Bocaege, Priscilla Ulguim, Andrew Wilson, Suzy White, Cara Hirst, Marta Alfonso-Durruty and Siân Smith.

\section{Acknowledgements}

The authors would very much like to thank those that attended the Digital Bioarchaeological Ethics and Methods Session at WAC 8 for their participation and contribution to the discussion. We would also like to acknowledge the many contributions of our colleagues and contacts from all spheres who have shared their experiences and practices.

\section{Open Access}

This article is distributed under the terms of the Creative Commons Attribution 4.0 International License (http://creativecommons.org/licenses/by/4. $0 /$ ), which permits unrestricted use, distribution, and reproduction in any 
medium, provided you give appropriate credit to the original author(s) and the source, provide a link to the Creative Commons license, and indicate if changes were made. 